\section{RECENT PROGRESS IN DERMATOLOGY.}

BT E. WIGGLESWORTH, H. D.

TUBERCULOSIS OF THE SKIN.

JARISCH and Chiari contribute ${ }^{1}$ the case of a man aged forty-two, who presented himself for the treatment of a crust reaching over the left ear like a bow. Bome slight pain. The crust was removed. A reddish-yellow, granulating ulceration, shaped like a fiveleaved clover, then appeared, its pitted floor covered with pus, movable on its base, and with irregularly notched, swollen, red, precipitous edges. Cervical glands somewhat swollen. Slight pharyngitis. Moderate dullness over right upper Jung belind. Syphilis was excluded by absence of infiltration, of lardy base, and of pain; epithelioma by the character of the margin and the short duration of the diseased process. Nor did the ulcer resemble that from lupus or from scrofula. After the lapse of three weeks the patient complained of a sore throat, and an inspection of the pharynx showed miliary tubercles, and small ulcerations due to the breaking down of these. Tuberculosis of the skin was now diagnosticated. The ulcer steadily enlarged, and the patient died six weeks later.

Autopsy. Ulcers in trachea, pharynx, and intestine. Cheesy nodules and caverns in the lungs. Caseous degeneration of the submaxillary and cervical lymph glands. The ulcer so deep as to expose the temporal muscle and branches of the facial nerve and superficial temporal artery. The borders of the ulcers of the skin and of the pharynx were full of miliary tubercles. Chiari has seen only six cases of tuberculosis of the skin. These occurred upon the under lip, and never extended over more than ten square centimetres.

\section{XANTHOMA.}

Chambord describes ${ }^{2}$ a case of xanthoma of both eyebrows, upper eyelids, and external canthi, more marked on the right side. The necropsy showed ecchinococcus cysts of the lungs and liver, tuberculosis of the omentum, and xanthoma of the larynx, trachea, and bronchi. Histologically, Chambord regards this disease as an irritative process seated in the connective tissue, and causing hypertrophy of this tissue around vessels, sweat glands, and primitive nerve bundles, the newformed elements then fattily degenerating. In the flat form of xanthoma cell formation and degeneration keep pace with each other; in the tubercular form the latter is less rapid than the former.

\section{HEREDITARY SYPHILIS.}

Professor Zeissl contributes ${ }^{3}$ the results of a thirty yeurs' experience to the at present much-agitated question of the hereditary transmission of syphilis. It is not so much pathological appearances as the ways and means of transmission which are of importance. It is now generally accepted that at the moment of conception syphilis may be communicated to the foetus by the semen of a syphilitic father or the ovum of a syphilitic mother. There is no must to this rule, and Zeissl has observed nine cases of healthy children born of parents one of whom had secondary syphilis. As the disease fades in the parents so fades the probability of transmission to the fœtus, though the possibility remains as

1 Vierteljsch. f. Dermatol. u. Syphilis, vi., 2 and 3, page 265, 1879.

2 Ann. de. Dermat., etc., t. x., No. 4, page 241, 1879

8 Wien. med. Wochenschr., No. $4,1880$. long as the disease exists, though latent, in either parent, much more so if in both. The fewer and fainter the symptoms in the parent the less grave are they in the child. Where the disease is latent in the parent the child may appear healthy at birth, and only after three, six, or more months evince the symptoms of hereditary syphilis. Active syphilis in the parents causes abortion, still-births, or early death of child. Zeissl believes also (1) that the previously healthy mother is infected by her child of a syphilitic father, though she be not directly infected by him, that is, the man; and (2) that the child of healthy parents may be infected in the womb of, and by, its mother, should she acquire syphilis during her preguancy. 'This last, the "iufectio in utero" of Kassowitz, is proved by a case reported by Zeissl's son, and is accepted by Guibout, Desprès, Jullien, Basseraux, etc. Not so easy is it to prove that a healthy mother can be infected by her syphilitic fotus. Still there is one case on record of a mother being infected by nursing ber own hereditarily syphilitic child; and Caspari has inoculated syphilitic virus upon various parts of the body of an apparently healthy mother of a syphilitic child without effect. Zeissl does not accept Kassowitz's theory, that without going through a disease one can yet be so penetrated and permeated by it as to possess immunity from contracting it; for he almost daily examined for two years the previously healthy wife of a syphilitic husband, and found no primary lesion, yet she during this time bore two hereditarily syphilitic children, who died soon after birth, herself failing in health and losing her hair soon after the first conception, and showing during the second pregnancy a squamous syphiloderm of the palms. In another case he treated a man in 1865 who married in 1867. He examined the wife almost daily. She bore a syphilitic child in 1868 , and another in 1869. After the first delivery the wife had general syphilis, but never an initial selerosis. He has seen also many analogous cases. 'The fotus, then, being syphilitic, the mother is almost invariably so also. A woman can also, according to Zeissl, become infected by the semen of a man with recent but latent syphilis without being impregnated, and he states that he has seen numerous such cases. Here the woman shows late forms like painful periostitides. More frequently, however, the mother is infected by the foetus through the placental circulation, and may show symptoms belonging to the condylomatous period of the disease, or, as in galloping syphilis, those of the gummous stage. Such women may subsequently bear healthy children to a healthy man, or even to the same man if he has become healthy.

\section{TREATMENT OF PRURIGO BY PILOCARPIN.}

Simon, of Breslau, ${ }^{5}$ in view of the physiological properties of pilocarpin, has experimented with it in the treatment of such diseases of the skin as are especially characterized by absence of any secretion from the sweat glands, and particularly of prurigo. This disease is practically unknown in America, only three or four cases having ever been recorded. Into adults he injected daily, subcutaneously, one gramme of a two per cent. solution of muriate of pilocarpin. Also, at times, a syrup of jaborandi was employed internally when the injections were contra-indicated. This syrup is prepared by pouring fifteen parts of boiling water

4 Guibout. Nouvelles Leçons cliniques sur les Maladies de la Peau, 1879, page 154.

5 Berliner klin. Wochenschr., No. 49, 1879. 
over three parts of jaborandi leaves, and dissolving in the filtrate eighteen parts of sugar. For adults the dose is two to three teaspoons, for children in proportion. After the application of the remedy the patient was put to bed for three hours, between blankets. Patients with psoriasis could not be made to perspire; those with prurigo sweated profusely. The syrup of jaborandi in moderate doses (as above) was well borne. The pilocarpin injections and larger doses of jaborandi syrup caused, while producing the effects desired, salivation, in some cases nausea, and in a few vomiting, requiring cessation from the use of the drug. The good effects of the treatment in most cases were very apparent. The itching ceased after one or more applications, the exanthem diminished, the relapses became fewer, and, the scratching ceasing, the skin soon became smoother, softer, and less wrinkled. The swelling of the inguinal glands disappeared, and the patients rarely needed more than a month of treatment. Combined with tar externally, even more rapid progress was achieved, the patient sweating for twelve hours and being tarred the other twelve.

PATHOLOGY AND THERAPEUTICS OF FURUNCLE AND ANTHRAX.

Hofmoke, in a lecture ${ }^{1}$ upon carbuncles, states that during the 'last six years he has treated forty-three cases, and many more of furuncles. Four anthraces were treated by cold or warm cataplasms, operation, and compress wet with lime water, sulphate of copper, or chlorate of potassium. One of these required a second, and one even a third, operation. Thirtynine anthraces were treated otherwise, and the patients were rapidly and pleasantly restored to healtlı. The plan adopted was as follows: The skin and environs were thoroughly cleansed with a five per cent. solution of carbolic-acid water. Longitudinal and cross cuts were made, splitting the carbuncle and reaching into the sound tissue at each end, and penetrating downwards to the fascia limiting the necrosed tissues. The quadrants were then also incised freely, parallel with the base of the carbuncle, thus cutting the blood-vessels leading from the fascia to the skin, and, by relieving the stasis, limiting further necrosis and causing a more easy sloughing of tissues already necrosed. Gentle pressure was then applied to remove purulently degenerated material, and the wound thoroughly cleuned with a five per cent. solution of carbolic-acid water, and stopped with tampons of lint soaked in the same. A similarly treated mass of lint was laid over everything, then dry charpie, and finally plaster, or a bandage. After twenty-four hours of slight or no pain, the tampons of lint are to be soaked off with a two per cent. solution of carbolicacid water, dead matter removed, the wound washed carefully with a five per cent. solution, and dressed as at first, but now with merely a three per cent. solution of carbolic acid in olive oil, once or at the most twice daily, to avoid carbolic-acid poisoning. Lister's gauze under the tampons prevents adhesions. When wound is clean and bealthy, use ouly simple dressings till recovery.

\section{NON-VENEREAL SYPHILIS.}

In rather more than a third of all cuses of syphilis we find intentional or unintentional ignorance of whence or how the disease was acquired, with non-rec-

1 Wiener Klinik, October, 1879. ognition of the nature of the initial sclerosis until later symptoms appear. The laity still look upon syphilis as necessarily coming from a lesion upon the genitals of one person and necessarily received by the genitals of another, - two errors. The lesion serving origin of the virus may be situated anywhere upon the person infecting ; the excoriated spot receiving the contamination may be upon any part of the body of the person infected. V. Sigmund cited ${ }^{2}$ one hundred and sixtysix cases of extra-genital primary sclerosis. His assistant, Dr. Mracek, now adds ${ }^{3}$ eighty additional cases to this list. Of these, more than half (forty-four) were due to direct contact of syphilitic patients with nonsyphilitic persons, such as physicians, wet-nurses, ward tenders, midwives, pursuing their professional duties ; innocent women and children from a kiss; both sexes from scratching, sucking or biting, fingering, or " mistaken identity" (Juvenal), in war or love, when intoxicated or not. Mediate infection from sugar-teats, spoons, nursing-bottles, surgical instraments, pipes, clerical water-closets, tools (glass blowers'), and possibly toilet. utensils, goblets, or dishes, was less common, and, though not always susceptible of proof, in many of these: cases immediate contagion could justly be suspected. The reports of Jullien, Lancereaux, Aimé Martin, and Fournier" swell this list to four hundred and seventy. seven cases. More recently five cases have been reported by Zeissl, ${ }^{5}$ two by Weinberg, ${ }^{6}$ nineteen by $\mathrm{Hu}$ lot, ${ }^{7}$ Spillman, ${ }^{8}$ Bulkley, ${ }^{9}$ and Plumert. ${ }^{10}$

INFLAMMATION OF THE SKIN CAUSED BY A HITHERTO UNCLASSIFIED MITE.

Geber denies, in a clinical lecture,"1 the right to the term parasite of the various species of insects and fungi which merely irritate the skin, and would even recognize the itch insect or the " ringworm " fungus as mere causes of disease, classifying the resulting morbid processes under their appropriate histological or clinical headings. He describes the results of contuct with the skin on the part of a microscopic harvest mite, recently detected from Lower Hungary. Barley sent thence to Klausenberg was carried in sacks upon the backs of laborers from the railroad station. Within a few minutes these men were attacked by intense itching and burning, occurring at places which had been touched by a yellowish-brown powder falling from the sacks. This powder, sent to Professor Geber for examination, proved, under the microscope, to be composed of little animals, living or dead, and their rudiments. Examination of the laborers, ten days having now elapsed, showed inflammation of the skin still present. Geber persuaded a man who had not carried the barley before to carry a sack for a few minutes, thus obtaining the appearances of recent irritation. An urticaria appeared, and lasted for more than a day. Patients in the hospital were then sprinkled or rubbed with the powder, the succeeding inflammation being shown to be of three grades of intensity. The simplest was a severe urticaria, specially localized about the openings of the follicles, coufluent, lasting some thirty-six hours, the mite

\footnotetext{
2 Wiener med. Wochenschr., 1865.

8 Wien. med. Presse, Nos. 1, 2, 3, 4, 5, 1880.

1 Union méd., October 25, 1855.

5 Allg. Wien. med. Zeitung, 1878, Nos. 2 and 3.

6 Sitzungsb. der k. k. Ges. d. Aerzte, 1878.

7 Ann. de Dermatol. et de Syphiligr., 1878.

T. B. Curtis.

9 Archives of Dermatology, Philadelphia, 1879

10 Wien. All. med. Zeitung, 1879 . Nos. 49 to 51.

11 Wien. med. Presse, October 26, 1879, et seq.
} 
adhering to the epidermis, and dying in a few hours. The next grade was an eczema, lasting a week, with slight fever and loss of appetite. The third form was a dermatitis, with marked fever, followed by desquamation and pigmentation.

\section{ATIOLOGY OF ERYTHEMA NODOSUM.}

Neumann regards ${ }^{1}$ erythema nodosum as an idiopathic disease, for erythema papulatum, annulare, iris, and gyratum occur epidemically, and represent merely different stages of development of an erythema multiforme, whereas the change of either of these forms into E. nodosum, or vice versa, has never come within his experience. Hebra's original view of E. nodosum as a disease sui generis is maintained by Trousseau and Revillout. ${ }^{2}$ The diametrically opposed conception of E. nodosum as a mere symptom of the morbid condition of some internal organ is upheld by Wilson, $H$. Köbner, ${ }^{8}$ and Lewin. ${ }^{4}$ Lewin, in fact, regards this disease as an E. multiforme, believing that the size of the nodules upon the lower legs is due merely to the histological conditions there present, such as loose, distensible connective tissue and impeded circulation. Neumann denies this, and attributes the size of the nodules to the character and intensity of the disease process. Moreover, the disease has no annual relapses, no special tendency to occur in very young persons, and may accompany severe and even dangerous general conditions, being unlike, in these respects, E. multiforme. As the rule it is an acute disease, appearing with slight fever and rheumatic pains, especially attacking anæmic persons, and disappearing spontaneously in three to four weeks, not to return; or the nodules appear as symptoms of disease of other organs (endocarditis, pleuritis), or with rheumatism or pyæmia, in which cases the disease is of greater importance.

\section{MASTITIS AND PAROTITIS SYPHILITICA. ${ }^{5}$}

Syphilis of the pancreas has been described by Huber, Birch-Hirschfeld, Rokitansky, Lancereaux, Chvostek, Rostan; by the first in congenital syphilis, and by Klebs in a six months' fœtus. But other acinous glands are also, though rarely, affected. Of this sort are the "cancers" of quacks, where the disease yields to internal treatment, namely, potassic iodide. Per contra, syphilitic breasts have been excised as cancerous. Lancereaux ${ }^{6}$ justly claims the honor of first calling attention to syphilis of the glands of the breast. Sauvages, Maisonneuve, Icard, and others report cases of hard, knobby tumors of the breast in syphilitic patients disappearing entirely under the use of potassic iodide. Boeck reports ${ }^{7}$ the case of an old lady, from whose upper maxilla a tumor had been extirpated a year before, with syphilitic mastitis and gummatid, both yielding speedily to iodide of potassium. He has seen also two other cases. Where no other symptoms of syphilis are present the diagnosis may be difficult, the tumor presenting all the characteristics of scirrhus, even to the lancinating pains. Richet gives a case where a tumor like that in the breast was found in one calf of the leg by accident, just as the former was about to be excised, both dis-

1 Wien. med. Wochensch., No. 44, November 1, 1879.

2 Gaz. des Hôpitaux, 1874.

8 Arch. für Dermat. und Syph., 1869.

4 Charité-Annalen, 1878.

5 Wien. med. Wochenschr., No. 9, 1880 $18 i$

6 Traité historique et pratique de la Syphilis, Paris, 1874, page

7 Erfahrungen über Syphilis, page $\mathbf{1 6 5}$ appearing simultaneously under treatment by potassic iodide. No other symptom was present. Verneuil has demonstrated ${ }^{8}$ pathological preparations from a man with multiple gummata, one of them affecting the breast. Hennig ${ }^{2}$ found gummata of both breasts in making an autopsy of a woman, aged fifty-five years, and who had been for four years confined to her bed on account of syphilitic ulcerations of the knee. Syphilis of the breast, therefore, may appear now as a gumma and now as interstitial induration, as is the case with syphilitic disease of the liver, testicle, pancreas, etc. Lancereaux distinguishes between "syphilitic mastitis" (interstitial) and "gummous mastitis." Of the former be has seen one case, and he, as well as Hennig, reports three such cases as given by Ambrosoli. Lang also has seen one such case, and here the parotid gland was also affected, other sigus of syphilis being present as well. Lancereaux ${ }^{10}$ reports the case of a woman, aged forty-five years, with general syphilis and disease of the left submaxillary gland, seen afterwards also at the necropsy. Volkmann, under the title Cheilitis Glandularis Apostematosa, gives ${ }^{\mathbf{1 1}}$ an account of five cases of catarrhal inflammation of the labial glands, either with or without abscess formation. Three of these cases were syphilitic. The condition may have arisen by direct propagation in continuo from a catarrh of the mouth and jaws.

\section{FAVUS FROM THE CAT.}

Dr. W. G. Smith gives ${ }^{12}$ the case of a boy, aged two years, with an oval patch upon his back, the size of a dime, dry, and of the color of sublimed sulphur, the margin being lighter, and showing several characteristic favus cups. No eruption elsewhere. No other person in the family affected. A kitten in the house showed, on inspection, two dry, white, irregular patches. She was killed with chloroform, and crusts from the affected portions of the skin proved by microscopic examination to be composed of the mycelium and conidia of the Achorian fungus. Favus may be seen upon dogs, rabbits, canaries, and poultry, but it is least uncommon upon cats, who acquire it from rats and mice, upon whom it is by no means exceedingly rare. Dr. Smith gives another case, a girl, aged nine years, with some thirty spots upon the back. She had visited at the house of a friend, married, but childless, who allowed a cat to sleep with her, though the animal was covered with "sores." This animal died before it could be obtained, but a healthy kitten, obtained later from a neighbor, sickened soon after being brought to the house, showed upon its breast three round, scurfy patches, the size of a quarter dollar, and soon afterward died. 'This kitten also slepi with the woman, who, with her husband, showed round, scurfy patches at about the same time. Later, favus cups appeared upon the child.

\section{a SINGUlar Disease of the SKIN.}

Under this exasperatingly worthless title, Dr. Landon reports ${ }^{13}$ the following case: A healthy but anæmic woman, aged twenty-eight years, mother of two children, worked twelve hours, without resting, in

8 Traité historique et pratique de la Syphilis, Paris, 1874, page 186.

9 Arch. für Gynaek., 1871, page 350 .

10 Loc. cit., page 253 .

11 Virch. Arch., vol. l., p. 142.

12 Dublin Journal of Medical Science, December, 1879.

13 Berl. klin. Wochenschr., January 12, 1880. 
cooking and bringing water on a stormy day. She then noticed (Friday, August 21, 1878) an erysipelatous swelling of the left hand, the back of it being puffed out like a cushion, bright red, not œdematous, and itching slightly; the palms less so; the fingers free. By the evening of Saturday the hand appeared normal. On Sunday morning the right hand swelled in the same way, and remained so until evening. After an intermission of eight days the left foot, and inside of leg as high as the knee, swelled, and caused pain as well as itching. As this condition disappeared, the right foot and leg took on the same appearances, which disappeared in two days. After a pause of four weeks a puffiug up of the upper lip occurred, beginning at the angle of the mouth, on the left side, and extending around the whole mouth, healing as it advanced, so that a third only of one lip was at any one time affected. Before this had quite disappeared the right cheek and eyelids became affected (October 10th), so that the eye was closed. 'This state of things had disappeared in twenty-four hours, by which time the left foot was again enlarged. The skin of the left shoulder swelled, and grew painful a day later, and remained thus for two dxys, by which time the right foot had taken its turn again. By the next day all these parts were normal, but the right buttock had become enlarged, painful, red, and plainly marked with an erythema nodosum. This disappeared within three days. A month later, the patient being healthy in the interim, the left foot repeated the process, which lasted, however, but two days, and has not since appeared. There was no fever at any time, but tolerably profuse perspiration, especially at night, which was not the case when the patient was in good health. Urine normal in quantity and quality. Joints unaffected. Dr. Landon appends his own case, which was similar, though less marked. Quinine, cold douches, the constant stream, and faradization had no effect. He regards the disease as due to a spinal irritation, from exposure and hard work, causing paralysis of the sympathetic nerve, especially of those branches going to the smaller arteries, the relaxation of which would account for the swelling. $\mathrm{He}$ does not, however, attempt to explain the typical intermittent, nor, in the case of the lips, gradually progressive swelling.

( $T$ o be continued.)

\section{fteportg of Societicg.}

\section{PROCEEDINGS OF THE SUFFOLK DISTRICT MEDICAL SOCIETY.}

\section{JOHN B. SWIFT, SECRETARY PRO TEM.}

The meeting was called to order by Dr. Hodges at 7.40. 'Thirty-four members present.

Dr. E. H. Bra DFord reported a case of Genu Valgum, and showed the patient, where osteotomy had been performed. He said that the pathology and treatment of knock-knee had undergone a change during the past few years. It was formerly supposed to be due to a contraction of the outer hamstring or the exterual lateral ligament, and to remedy the deformity these parts had been divided. It really is due to an abnormal difference in the planes of the two condyles; and therefore it is impossible for the leg to become straight by simply dividing the external lateral ligament. In order to cure a case it is necessary that the two condyles be brought into the same plane. This is accomplished by the growth of the condyles, and may be effected in certain cases by the constant use of an apparatus. He mentioned a case of this kind. The child was four years old, and hardly able to walk on account of extreme knock-knee of both limbs. The apparatus was worn for two and one half years, and the deformity almost entirely corrected without an operation. For the last six months no apparatus has been worn, and there has been no relapse.

In cases where the limb cannot become straight under the use of apparatus, that is, where the bone will not grow, various operations have been devised. Meyer made a section of the tibia. Schede removed a wedge-shaped piece from the tibia. Annandale opened the joint and sawed off the condyle. This case recovered with a stiff kuee. Ogston divided the condyle with a subcutaneous saw. 'This has been done over two hundred times, and has been quite successful. There have been some deaths. In order to avoid opening the joint Chiene and Macewen cut a wedge-shaped piece from the bone above the condyles on the inner side. M. Delore has operated three hundred times by breaking the leg. Supposed to be a separation of the epiphysis and rupture of the external lateral ligament.

Dr. Bradford's method was suggested by McCormick. In order to preserve the length of the limb the section is made on the outside of the bone. A chisel is entered as near the line of the epiphysis as possible; then straightening the leg separates the epiphysis and leaves a wedge-shaped gap, which is allowed to fill up by granulation, and the two condyles are thus brought upon the same plane. The joint is not opened and the operation is done with antiseptic precautions.

Cass. The patient was eleven years old, and suffered with deformity of both limbs. The right leg was operated on July 20th, and a plaster-of-Paris bandage was immediately put on over a Lister dressing. A fenestrum was cut in the bandage and the dressing turned. back over the edges of the feustrum. A second antiseptic dressing was then applied over the wound. The plaster bandage was removed in four weeks, and the deformity was found to be corrected. The patient suffered no pain whatever. The left leg was operated on four weeks ago, in the same manner. The right leg can now bear the weight of the body, and motion at the knee-joint is perfect. The left leg is still on a splint, and is not allowed to be used.

Dr. A. T. Савот opened the discussion. He sail that he had seen Billroth break the tibia and fibula with the osteoclast in two adults for this deformity. Although one arm of the osteoclast was adjusted to the thigh, the bones broke where the crutch was applied. In children this procedure might separate the epiphysis. He thought it unwise to operate on a child uuder four years, for below that age there was a tendency for the deformity to correct itself. If, however, the deformity interferes with standing or locomotion, it should be done before this age. Osteoclasis can be done within two or three inches of the joint without danger. The last case in which he operated was broken in-ide of three inches of the joint. 'Thinks that in children osteotomy is the operation, but in adults where the epiphysis has united osteoclasis should be done. Osteotomy in adults does not do as well as in children. Unless antiseptic precautions are taken thinks osteoclasis to be preferred.

Dr. Bradforo thought that osteoclasis did not dif- 